\title{
ENSINO DO PORTUGUÊS PARA FALANTES DE OUTRAS LÍNGUAS: ANÁLISE DAS TRANSFERÊNCIAS DOS PADRÕES DA LM NA ESCRITA
}

\author{
Susiele Machry da Silva \\ Universidade Tecnológica Federal do Paraná \\ Luciene Bassols Brisolara \\ Universidade Federal do Rio Grande
}

\section{RESUMO}

Este estudo versa sobre a aquisição do português brasileiro por falantes de outras línguas, mais precisamente no que se refere à escrita. A proposta foi investigar como esses falantes desenvolvem o sistema escrito na língua não nativa, observando possíveis influências dos padrões de suas línguas nativas, mais precisamente no que se refere aos aspectos fonético-fonológicos e morfossintáticos. O estudo foi desenvolvido a partir de uma amostra de produções escritas coletadas com imigrantes, sendo estes domiciliados nas cidades de Rio Grande - RS e Pato Branco - PR. Ao todo foram incluídos na amostra 17 informantes, sendo sete falantes nativos do crioulo haitiano e 10 falantes nativos do espanhol. A análise revelou que, com relação aos aspectos fonético/fonológicos, tanto os haitianos quanto os hispânicos apresentam na produção escrita alterações relativas ao fonema e ao acento e, considerando os aspectos morfossintáticos, as alterações evidenciadas dizem respeito à concordância nominal e verbal, regência preposicional, bem como questões de mudança de gênero gramatical.

PALAVRAS-CHAVE: aquisição de língua; imigrante; aspecto fônico; aspecto morfossintático; escrita 


\section{1 lntrodução}

A imigração constitui uma prática recorrente e contínua no Brasil e no mundo; um movimento histórico demarcado por diferentes motivações, relacionadas a fatores sociais, políticos, econômicos, ambientais, entre outros. Neste cenário, a América Latina, historicamente, "foi um importante destino para os emigrantes no período das grandes migrações" (LANZA; LAMOUNIER, 2015, p. 91). O Brasil desde os tempos de sua colonização tem sido visto como uma alternativa de recomeço a europeus e outros povos que buscam por estudo, trabalho ou mesmo melhores condições habitacionais.

Ao pensar no contexto da imigração, deve-se também pensar na integração dos imigrantes no novo país, o que inclui o acesso à língua dessa nação. O conhecimento do novo idioma torna-se, muitas vezes, uma condição para que esse imigrante seja socialmente inserido em um contexto social, onde a sua língua tende a assumir uma condição minoritária.

Nas práticas sociais cotidianas a que o imigrante passa a ser engajado no novo país, prevalece majoritariamente a língua falada. Com isso, a depender da situação e do propósito da imigração, não há uma aparente necessidade do conhecimento e do acesso à escrita. Não obstante, parte-se do entendimento de que o domínio da língua em suas diferentes modalidades torna-se uma ferramenta indispensável para a inserção do não nativo nas esferas sociais que envolvem não apenas acesso ao trabalho, mas também acesso ao estudo, e a direitos que melhor se assemelham aos nativos. Ao passar a viver em outro país, é importante que o imigrante possa apropriar-se de sua cultura, de sua língua, usufruindo de todos os meios que possam garantir-lhes melhor condição de vida; para isso, é essencial o domínio da língua nas suas diferentes habilidades.

Ademais da prática imigratória recorrente, são ainda constantes no Brasil, assim como em diversos países, os movimentos de estudantes, por intercâmbio ou outras práticas, que temporariamente passam a viver em um novo país. Mesmo contando com períodos de estadias na maioria das vezes curtos, esses estudantes, da mesma forma que outros imigrantes, sentem a necessidade de ter o acesso ao idioma do novo país, ainda que com propósitos distintos. A exigência do conhecimento do idioma não nativo torna-se evidente não só nos espaços escolares e 
acadêmicos, mas também nas interações sociais necessárias ao estudante imigrante.

Frente ao exposto, este artigo objetiva investigar e analisar como imigrantes, atualmente domiciliados no Brasil, desenvolvem a escrita no português brasileiro, língua não nativa. A proposta contempla uma análise de produções textuais dos imigrantes, com vistas a observar possíveis influências de sua língua na escrita, assim como investigar quais aspectos da gramática da nova língua precisam ser aprendidos pelo imigrante, mais precisamente no que tange aos aspectos fonético-fonológicos e morfossintáticos. O estudo parte de uma amostra de 17 informantes, pertencentes a dois grupos: (i) imigrantes haitianos e imigrantes nativos do espanhol domiciliados na cidade de Pato Branco - PR e (ii) imigrantes nativos do espanhol domiciliados na cidade de Rio Grande - RS. Ambos os grupos possuem conhecimento básico do português, adquiridos em cursos no Brasil.

Os dois grupos investigados diferenciam-se quanto aos propósitos da imigração e quanto às práticas de uso da língua não nativa. Os imigrantes haitianos vieram ao Brasil, em sua maioria, motivados por incidentes ambientais e buscam reconstruir suas vidas, almejando emprego e estabelecimento. Os propósitos que permeiam o aprendizado do português por esse grupo são bastante específicos, uma vez que se centram primordialmente no ingresso ao mercado de trabalho e nas interações cotidianas básicas, que envolvem comunicação na língua não nativa.

Diferente da imigração haitiana, os imigrantes nativos do espanhol estão no Brasil temporariamente por razões de estudo e utilizam a língua portuguesa em contextos mais formais que envolvem habilidades de fala, leitura e escrita. Além disso, ressalta-se o fato de que esses imigrantes temporários, geralmente, possuem maior tempo de convivência com falantes nativos da língua portuguesa, estabelecendo vínculos de relação social além do estudo.

Embora, pelos fatos expostos, não seja possível estabelecer comparações entre os dois grupos, pela premissa de que parte este estudo, torna-se relevante observar como esses grupos, ambos atualmente com acesso ao português formal, desenvolvem o processo de escrita na língua não nativa. $\mathrm{O}$ entendimento é de que independentemente da diversidade e das práticas que subjazem o processo de aprendizagem do idioma, esses imigrantes transferem para escrita os padrões de sua língua nativa e, outras vezes, deparam-se com diferenças entre as gramáticas das línguas, 
precisando reorganizar seu conhecimento, de forma a acomodar os novos padrões da língua-alvo. Frente a isso, o levantamento e a análise dos dados de escrita podem vir a auxiliar no preparo de material didático a ser utilizado em cursos de português para falantes estrangeiros.

\section{Sobre as línguas em estudo}

As línguas contempladas por este estudo são o crioulo haitiano e o espanhol. Os haitianos possuem como língua materna o crioulo haitiano, enquanto para os imigrantes nativos do espanhol a língua materna é o espanhol hispano-americano, visto ser o grupo constituído por pessoas oriundas de países da América Latina.

O crioulo haitiano é a língua materna e oficial do Haïti; possui como base o francês, mas também apresenta em sua formação características das línguas africanas (PIMENTEL; CONTIGUIBA; RIBEIRO, 2016). Os vínculos do crioulo haitiano com essas línguas estão relacionados, historicamente, à necessidade comunicativa e também econômica e social, configurando-se em diferentes dialetos com maior ou menor grau de prestígio, de acordo com as relações de poder e status. As bases africanas do crioulo haitiano surgiram das necessidades comunicativas que envolviam os então escravos e os colonos franceses, sendo atualmente a língua oficial da ilha. O francês, por sua vez, desde sua origem até os dias atuais, ocupa um espaço importante nas interações comerciais e sociais das camadas sociais mais altas. Ainda hoje o francês, portanto, ocupa um espaço importante nas relações econômicas e em algumas escolas, configurando-se como segunda língua em parte da ilha.

Por sua origem e relação com o francês, o crioulo haitiano, equivocadamente pode ser interpretado como uma simplificação dessa língua. Nesse sentido, de acordo com Spears (2010), é importante salientar que o crioulo possui sua própria gramática, sendo diferente do francês: "Não se pode usar a gramática do Francês como um modelo para entender a gramática do crioulo" "(SPEARS, 2010, p. 3). A atribuição de um sentido de "simplicidade" ao crioulo haitiano tem relação com o fato de não haver nessa língua, segundo o autor, por exemplo, exceções a regras gramaticais e sufixos de inflexões verbais para tempo, pessoa e número.

Para Villeneuve, Siegel e Valdman (2013), o crioulo haitiano apresenta um alto grau de padronização em relação a outras línguas de base francesa. Segundo os autores, a norma escrita do crioulo haitiano é baseada no discurso dos monolíngues da capital de Port-au-Prince e não na 
variedade pertencente aos bilíngues, economicamente mais poderosa. Por essas questões, preservam-se características como: não arredondamento das vogais frontais; não pronúncia do " $r$ " em sílabas finais; não flexão do gênero gramatical em artigos e adjetivos. Considerando esses aspectos, nota-se que a gramática do crioulo haitiano é bastante simplificada, se comparada à gramática do português, o que vem a refletir no ensino/ aprendizagem da língua, majoritariamente na utilização dos verbos, nas flexões de gêneros e nas questões relativas à pronúncia.

Quanto aos aspectos de pronúncia, com base em Cadely (2004), o crioulo haitiano, compreende um sistema vocálico composto por sete vogais orais, com distribuição semelhante ao sistema do português brasileiro, no que tange aos padrões de altura e anterioridade. Para essa língua é também distintivo um sistema de vogais nasais, que compreende cinco vogais, distribuídas em altas médias e baixas. Já o quadro de consoantes do crioulo haitiano é composto por 19 consoantes, segundo o autor, incluindo as aproximantes [w], [ч] e [Y]. O sistema de consoantes é também muito semelhante ao do português; sem, no entanto, haver a oposição entre as liquidas $/ 1 /-/ \Gamma /-/ r /$, constituindo uma das dificuldades para haitianos na pronúncia do português (MARTINS, 2013; MACHRY DA SILVA, 2017; SILVA, 2015).

O espanhol, por sua vez, é um idioma falado no continente americano - Argentina, Bolívia, Chile, Colômbia, Costa Rica, Cuba, Equador, El Salvador, Honduras, Guatemala, México, Nicarágua, Panamá, Peru, Paraguai, Porto Rico, República Dominicana, Uruguai e Venezuela -, no europeu - Espanha, no africano - Guiné Equatorial, cidades espanholas no norte da África, e também, como segunda língua, no norte de Marrocos - e no continente asiático - em Israel e nas Filipinas (HUALDE, 2010).

No nível morfossintático, o idioma apresenta um sistema pronominal com diferenças entre formas tônicas e átonas (ex.: mí/me; tú/te) e, na terceira pessoa, os pronomes de 'complemento direto' apresentam as formas lo(s), la(s) e os de complemento indireto, as formas le(s) (RODRÍGUEZ PUÉRTOLAS et al., 2004).

No nível fonológico, o sistema é constituído de cinco vogais orais, não havendo distinção fonológica entre vogais médias baixas e médias altas, como ocorre no português brasileiro e no crioulo haitiano. Diferentemente do crioulo haitiano, as vogais podem ser nasalizadas, mas essa nasalidade é de natureza alofônica e surge em contextos específicos (NAVARRO TOMÁS, 2004). Com relação ao sistema consonantal, segundo 
a Real Academia Española e a Asociación de Academias de la Lengua Española (2011), existem dois subsistemas, um mais generalizado e outro mais restrito. $\mathrm{O}$ mais geral é constituído de 17 fonemas, não distinguindo $/ \mathrm{N} / \mathrm{de} / \mathrm{j} / \mathrm{e} / \mathrm{s} / \mathrm{de} / \boldsymbol{\theta} /$. A maior parte dos falantes de espanhol hispano-americano, os da Andaluzia e das Ilhas Canárias empregam esse subsistema. O outro subsistema é constituído de 19 consoantes, havendo distinção fonológica entre $/ \mathrm{N} / \mathrm{de} / \mathrm{j} / \mathrm{e} / \mathrm{s} / \mathrm{de} / \boldsymbol{\theta} /$, sendo os falantes nativos do espanhol peninsular, com exceção dos da Andaluzia e das Ilhas Canárias, os que apresentam esse subsistema.

\section{Metodologia}

O estudo foi desenvolvido a partir da amostra de produções textuais feitas por imigrantes nativos do espanhol e do crioulo haitiano, domiciliados, no momento da coleta dos dados, no Brasil, nas cidades de Rio Grande - RS e Pato Branco - PR. Para participar do estudo os participantes deveriam estar residindo no Brasil por um tempo mínimo de cinco meses, estar frequentando curso de português, ofertado na Universidade Federal do Rio Grande e na Universidade Tecnológica Federal do Paraná. Ao todo, foram selecionados 17 imigrantes, 10 nativos do espanhol (Venezuela - três; Peru - quatro e Colômbia -três); e sete nativos do crioulo haitiano, da República do Haiti. O tempo de residência dos informantes, considerando o grupo como um todo, compreende um período entre cinco meses e dois anos. No primeiro contato com os informantes foram explicados os procedimentos da pesquisa e foi solicitado que, se de acordo, estes assinassem a um Termo de Consentimento Livre e Esclarecido ${ }^{2}$.

\subsection{Sujeitos da pesquisa}

Para a composição da amostra levou-se em conta primeiramente o fator relacionado a ser imigrante, ou seja, ter migrado para o Brasil e estar residindo no país, por um tempo mínimo de cinco meses. Fazem parte do grupo de nativos do crioulo haitiano, sete informantes, cinco do sexo masculino e dois do sexo feminino, com idade entre 22 e 42 anos (média de idade 33,14 , DP =7,77); e dez nativos do espanhol, oito do sexo masculino e dois do sexo feminino, com idade entre 20 e 33 anos (média de idade $27,92, \mathrm{DP}=1,41$ ). Embora não se tenha propriamente um teste para medir o conhecimento dos participantes no português, tomou-se o cuidado de que todos eles tivessem o conhecimento básico da língua, já tendo frequentado um tempo mínimo de dois meses de curso. 
Destaca-se, ainda, que os integrantes de ambos os grupos investigados revelam, em sua maioria, ter conhecimento de outras línguas, tais como o inglês, majoritariamente, e o francês. No caso dos imigrantes hispânicos, estes não possuíam conhecimento do crioulo haitiano; enquanto que, dos imigrantes haitianos, dois informantes, tinham conhecimento do espanhol. No grupo de informantes da cidade de Pato Branco, os haitianos e os hispânicos compartilhavam do mesmo espaço de aprendizagem do português, vindo eles a usufruírem dos mesmos métodos de ensino. Os imigrantes da cidade de Rio Grande, por sua vez, eram todos falantes nativos do espanhol que frequentavam curso de português no nível intermediário. Conforme será explicado na próxima seção, tomou-se $o$ cuidado de seguir os mesmos métodos, nos dois grupos investigados para o encaminhamento da produção textual.

\subsection{Instrumento da pesquisa}

Após obter o consentimento dos informantes para a realização do estudo, procedeu-se à aplicação de um questionário com vistas a conhecer as características dos participantes. Além de questões gerais como idade, sexo e tempo de curso, o questionário buscou elucidar questões relacionadas ao tempo de residência no Brasil, acesso ou conhecimento prévio do português, conhecimento de outras línguas, e também ao tempo de uso do português nas situações cotidianas. Embora não seja foco deste estudo, o conhecimento do grupo quanto a esses fatores individuais auxiliou na escolha das temáticas e, principalmente, quanto à formação de um perfil dos participantes.

Na etapa seguinte, cuidou-se da seleção das temáticas a serem trabalhadas nas produções textuais. Foram selecionadas três temáticas, as quais foram inicialmente apresentadas e contextualizadas nas aulas; tomou-se ainda o cuidado de que os temas fossem familiares aos informantes, tratando de aspectos do cotidiano e de práticas comuns de linguagem. A partir desses critérios, as temáticas contempladas foram: "Minha casa", "Uma carta para minha família" e "Brasil: um país hospitaleiro?".

Antes da realização das produções textuais, foi feita uma abordagem prévia de cada assunto por meio de textos, cartas, vídeos, imagens, músicas e trabalhos práticos que buscaram contextualizar os temas. As produções foram escritas durante o segundo semestre de 2017, sendo aplicada cada uma em datas distintas. Os informantes realizaram as três produções textuais em sala de aula, diretamente em português, sem computador e sem 
auxílio de dicionário ou de outros materiais. $\mathrm{Na}$ introdução da produção buscou-se dar uma orientação bem clara aos alunos. Faz-se a ressalva de que, embora não nas mesmas datas, os dois grupos investigados realizaram as mesmas produções textuais e seguiram os mesmos critérios de aplicação.

Na temática sobre "Minha casa", os informantes foram instruídos a descrever sua casa de maneira detalhada. Poderiam ainda falar sobre sua casa no Brasil e sua casa no país nativo, falando dos seus sentimentos e saudade, das pessoas com quem moram e com quem moravam em seu país. Na segunda temática, "Uma carta para minha família", os informantes foram incentivados a escrever uma carta direcionada para um familiar de seu país, contando como estavam se sentindo no Brasil, de suas tarefas diárias e de seus sentimentos. Por fim, na última temática, após tratar de várias questões de imigrantes no Brasil, os informantes foram convidados a refletir e escrever sobre o tema "Brasil: um país hospitaleiro?", falando sobre como foram recebidos no país, sobre suas relações com os nativos, dificuldades enfrentadas em geral.

Das três produções textuais recolhidas dos alunos, selecionou-se apenas uma de cada informante para a análise. O motivo de escolher apenas uma produção deveu-se ao fato de que alguns informantes não realizaram todas as produções textuais, por terem faltado à aula em alguns dias e, também, pelas questões de familiaridade com as temáticas, em que se observou que os participantes mostraram maior facilidade para desenvolverem uma ou outra proposta, produzindo textos bastante curtos em alguns casos, os quais foram excluídos da análise. Com base nessas informações, optou-se por trabalhar com um texto de cada participante, sendo o critério de seleção o tamanho e produtividade a partir do tema.

\section{Análise e discussão}

Por compreender uma investigação com grupos de sujeitos oriundos de diferentes países, com razões de imigração distinta e com diferentes características, que dificultam generalizações e comparações diretas, a análise contemplou produções individuais, com a separação dos dois grupos investigados, nativos do crioulo haitiano e nativos do espanhol. A partir das produções textuais recolhidas, foram levantados critérios para a análise dos textos em ambos os grupos, contemplando aqueles aspectos mais recorrentes na amostra, ficando assim delimitado: (1) Troca ou substituições de fonemas; (2) Supressão, inserção ou troca da posição do acento; (3) Aspectos morfossintáticos. 


\subsection{Análise das produções textuais dos imigrantes haitianos}

No primeiro critério, trocas, inserções ou supressões de fonemas, foram analisadas as substituições de um fonema por outro, bem como a inserção ou supressão de fonemas. Nesses casos consideram-se, seguindo a concepção de Zimmer e Alves (2006), as possíveis transferências dos padrões grafo-fônico-fonológicos, da L1 para a nova língua. Essa relação nem sempre é direta ou facilmente previsível, no sentido de que um mesmo fonema pode ter na escrita diferentes representações.

Observaram-se, quanto a esse critério, nas produções textuais dos haitianos, casos em que houve a troca de fonemas, como o observado entre o / $/$ / e o tepe $/ \mathrm{r} /$, como exemplificam as formas coroca para coloca, sara para sala e bora para bola. Nesses casos, observa-se tanto a realização do tepe [r] para /1/, como a realização de [1] em lugar do tepe /r/. Pelo fato de não haver o contraste entre a lateral e o tepe na língua nativa dos aprendizes, essa troca entre os fonemas, difícil para os aprendizes na pronúncia e percepção (MARTINS, 2013; MACHRY DA SILVA, 2017), era esperada na escrita.

Em outros casos, observa-se a troca entre a vibrante e a lateral /1/, em formas como moler para morrer calo para carro. A vibrante é também substituída na escrita por outra consoante, a exemplo de garrafa escrita como gavafa. A vibrante $/ \mathrm{r} /$ não está presente no crioulo haitiano (CADELY, 2004), o que explica sua substituição por outros fonemas na produção escrita dos haitianos.

Os dados de troca, substituição ou supressão de fonemas permitem, ainda, observar o registro da troca entre os grafemas "s" e " $\mathrm{z}$ " na escrita, com exemplos como: empreza e faser. Nesse caso, os dois fonemas estão presentes no crioulo haitiano, sendo que a substituição de um grafema por outro na escrita sugere-se estar associada à relação fonema/grafema, em que no português o /s/ apresenta o som de [z] nas formas empresa e fazer. Cabe salientar que este tipo de dificuldade não é exclusivo dos estrangeiros. Na aquisição de português como língua materna, o mesmo fenômeno é evidenciado tanto na escrita infantil quanto na aquisição da escrita por adultos (MIRANDA, 2010, BRISOLARA, 2012). Ou seja, a esses aspectos atribui-se a necessidade de o aprendiz entender como os sons da língua são ortograficamente representados na língua-alvo. 
Ainda com relação a esse critério, observa-se dificuldade dos imigrantes haitianos na escrita dos dígrafos, como exemplificam casos com a supressão da vogal do dígrafo (ex.: consege para consegue), ou da inserção de uma vogal (cheguava por chegava). No crioulo haitiano, assim como em português, em sequências como "gu" e "qu" a vogal não é pronunciada; na língua, palavras como $<$ guitarre $>$ (guitarra) e $<$ qualité $>$ (qualidade) são pronunciadas como [gitare] e [kalité]. Nesse caso, sugere-se, ao fazer a relação do som com a sua correspondência ortográfica no português, o aprendiz suprime a vogal, com base em sua pronúncia.

Com relação ao segundo critério observado, supressão, inserção ou troca da posição do acento, foram encontrados nos textos casos em que ocorre a não realização do acento, casos de troca da posição do acento ou, ainda, a colocação do acento em palavras não graficamente acentuadas. O padrão de acento no crioulo haitiano é diferente do português. No português, o acento primário tem papel distintivo, como em sábia - nome - e sabia - verbo - (BISOL, 2013; LEE, 1997). Nessa língua, o acento pode recair sobre as três últimas sílabas da palavra. Considerando que o acento no português é sensível ao peso silábico, a ocorrência do acento gráfico possui relação com o acento prosódico, sendo utilizado, a exemplo, nas exceções das tendências naturais da língua (ex.: acento gráfico em paroxítonas terminadas em consoante). No crioulo haitiano, com base em Silva (2015), observa-se que o acento primário é previsível e, assim como no francês, tende a ser colocado ao final da palavra. Há, segundo a autora, na pronúncia de haitianos realizações como "hoJE" ou "onTEM" (p. 180). O acento do português constitui, portanto, para haitianos uma dificuldade no aprendizado do português tanto na pronúncia quanto na escrita da língua.

Nos dados de escrita coletados por este estudo, observa-se a dificuldade de haitianos com a atribuição do acento gráfico. São constadas escritas de palavras como familia, e dificil, com a omissão do acento gráfico. Em outros casos, contrariamente, há a inserção de acento em palavras como éstaremos e mèsa, esta última com acento grave em palavras que não são graficamente acentuadas no português. Desses casos, a omissão do acento aparece em grande parte das produções, o que pode estar associado à dificuldade do imigrante em entender as regras de atribuição do acento ortográfico no português, que é diferente da atribuição do acento em crioulo haitiano. No crioulo haitiano utilizam-se mais frequentemente o acento agudo (') e o acento grave ('), em formas como 
$<$ fèt $>$ (festa), <tèt> $\left(\right.$ cabeça) e <pòt $>$ (porta). O acento circunflexo $\left(^{\wedge}\right)$ não é utilizado na língua, assim como o til $(\sim)$, indicando a nasalização em palavras como mãe, escrita na língua como <mannan $>$ (VALDMAN, 1988).

Também foi evidenciada nos dados de escrita das produções haitianas a troca da posição do acento na palavra vôce e a inserção do acento em más (conjunção). A troca da posição de acento e o uso do acento circunflexo em "vôce" demonstra que há um reconhecimento do aprendiz da utilização desse acento na língua-alvo, diferente do que ocorre na sua língua; a troca da posição pode estar associada a como o aprendiz percebe a pronúncia e a tonicidade das sílabas da palavra no português. Por sua vez, a inserção do acento em "más", sugere-se estar associada ao conhecimento que esses aprendizes possuem do espanhol, em que esse acento é utilizado na ideia de comparação de superioridade (Pedro es más bonito que Paulo).

No terceiro critério foram analisados os aspectos morfossintáticos. Nesse caso, as línguas também seguem padrões diferentes quanto à utilização de pronomes, conjunções, verbos e concordância. Como relatado na seção sobre as línguas em estudo, a gramática do crioulo haitiano tende a ser mais simples do que a gramática do português no que tange a esses aspectos. $\mathrm{O}$ crioulo, por exemplo, não faz a flexão dos verbos em tempo ou pessoa; da mesma forma que não são flexionados os adjetivos e artigos (VILLENUEVE; SIEGEL; VALDMAN, 2013), diferente do português.

No que tange aos aspectos de concordância, observa-se com maior frequência a falta de concordância no sintagma verbal, em exemplos como: "eu vai trabalha", "eu tem gripe". Ou seja, constata-se a dificuldade dos aprendizes em fazer a conjugação verbal e a concordância entre o verbo e o sujeito, assim como o emprego do infinitivo. Atribui-se essa dificuldade ao fato de o crioulo haitiano, conforme evidenciado, não realizar a flexão dos verbos. A conjugação na língua é feita de forma bem mais simples em relação ao português, usando de partículas frente aos verbos que indicam tempo (VALDMAN, 1988).

Verifica-se, ainda, quanto aos aspectos morfossintáticos, a dificuldade de haitianos no emprego dos pronomes pessoais e na realização da flexão do verbo em pessoa, apresentando construções como: "vai pensa" "eu vai trabalha". De acordo com VALDMAN (1988), no crioulo haitiano os pronomes pessoais têm somente uma forma; assim como também a 
língua não faz distinção entre masculino e feminino. Estes constituem aspectos a serem aprendidos na construção sintática da gramática da língua-alvo.

Outro aspecto observado na escrita do português por imigrantes haitianos refere-se à troca de gênero, como exemplificam as construções: "tomou banho boa", "chegaram com suas diplomas", ou ainda, formas como: "minha quarto" e "um geladeira". No português, faz-se a flexão de gênero dos nomes com os elementos a ele relacionados, tais como determinantes e adjetivos, devendo haver a concordância entre esses termos. Diferentemente, de forma mais simples, o crioulo haitiano não faz a flexão de gênero, isto é, na língua não há flexão de determinantes e adjetivos de forma a fazer a concordância, modificando o nome. Da mesma forma, o substantivo no crioulo haitiano não possui a marcação do gênero como ocorre em português.

Observa-se, ainda, nas produções textuais dos imigrantes haitianos a omissão ou uso de forma não adequada de artigos, como em: "la vida", "eu limpa la casa". Ao utilizar a forma "la", o aprendiz faz uso do artigo como no crioulo haitiano, embora nessa língua esse artigo seja comumente utilizado para referir a um nome previamente mencionado (ex.: lèt-la" >> a carta), não antecedendo o nome como em português (VALDAMAN, 1988).

O uso de preposições também se revela de forma distinta na escrita dos imigrantes, normalmente ocorrendo o uso da preposição de forma inadequada, ou ainda, a omissão da preposição, como em: "gosto a minha casa", "de ali na empresa". No português, o uso da preposição obedece à regência de nomes e verbos, estabelecendo relações entre o termo regente e os seus complementos. No crioulo haitiano, de forma semelhante ao português, preposições são usadas para indicar movimento, lugar, entre outros; não obstante, nessa língua, verbos nem sempre têm construções com pronomes objetos, não necessitando algumas vezes da preposição (ex.: $<<L i$ mande mwen $>>$ ele perguntou por mim). Nesse caso, o não nativo não só necessita conhecer os tipos de preposição utilizados no português, como também ter conhecimento da regência, entendendo a relação entre os termos. 


\subsection{Análise das produções textuais dos imigrantes hispânicos}

Com relação ao primeiro critério, denominado 'trocas, inserções ou supressões de fonemas' foram identificadas trocas de fonemas e inserção de fonemas. A maioria dos casos diz respeito à troca de vogais. Nessas trocas, evidenciaram-se casos de alternância vocálica, motivada principalmente por alguns fatores: a) em português a palavra é grafada com uma vogal e em espanhol, com outra (ex.: viver/vivir; por isso/ por eso; b) influência da língua oral não nativa sobre a forma escrita (ex.: istou, muitu); c) casos de possíveis confusões derivadas das diferenças entre língua falada e escrita (ex.: emportar, lempas).

Houve, também, troca do fonema nasal $/ \mathrm{n} /$ do português pelo $/ \mathrm{n} / \mathrm{na}$ palavra 'ganhar' produzida como ganar. Ao realizar essa troca, o informante faz uso de um vocábulo do espanhol em que a pronúncia da nasal não se realiza como palatal, mas, sim, como alveolar.

Além disso, alguns informantes hispânicos apresentaram uma confusão no emprego de grafemas que representam os fonemas /s/ e /Z/ em português, como se pode observar em 'profesores', 'pesquisa' e 'zamba'. Essa confusão, provavelmente, foi motivada por influência do espanhol, já que, neste idioma, o fonema /z/ não faz parte do inventário fonológico da língua, existindo apenas a forma ortográfica ' $z$ ', que, em geral, é pronunciada como [s]. Além disso, em espanhol, não existe o dígrafo 'ss'.

Considerando os dados de inserção de fonemas, foram encontrados apenas três casos, ou seja, 'alunos', 'setores' e ‘tudo' escritos como 'alumnos', 'sectores' e 'toudo'. Nos primeiros dois casos, as palavras foram redigidas tal como em espanhol, no último caso, é possível que a existência de um só vocábulo em espanhol, ou seja, 'todo' para duas representações em português, ou seja, ‘tudo' e ‘todo’ possa causar confusão nos estudantes estrangeiros na hora de escolher a forma adequada para cada contexto.

Considerando o segundo critério analisado, ou seja, supressão, inserção ou troca da posição do acento verificou-se na produção dos alunos hispânicos casos de não colocação do acento, troca da posição do acento e, também, colocação de acento em palavras que, no português, não levam acento gráfico.

Algumas das produções inadequadas com relação ao acento são provenientes da influência das regras de acento do espanhol, língua nativa dos imigrantes pesquisados. É o caso de 'proprias, experiencia, e amá- 
veis. Em espanhol, são consideradas paroxítonas palavras terminadas em vogal em $-\mathrm{n}$ ou $-\mathrm{s}$ e oxítonas palavras terminadas em outras consoantes.

Com relação ao mesmo critério, também foram encontradas nas produções escritas em português as palavras 'viví, aquí, percebí'. A inserção de acento nessas palavras obedece às regras do espanhol, não, do português. Conforme a Real Academia Española e a Asociación de Academias Americanas de la Lengua Española (2011), são considerados 'desvios da norma geral' os casos em que palavras terminadas por vogais recebem acento gráfico na vogal que se encontra no final da palavra (aquí, viví, percibi ); palavras terminadas por consoante recebem acento gráfico na segunda sílaba da palavra ( mármol, revólver, virgen); palavras terminadas por consoante que recebem acento gráfico na terceira sílaba (génesis, espécimen, hábitat); e d) palavras que recebem acento gráfico na terceira sílaba se a penúltima sílaba tem coda (rémington).

Também considerando o segundo critério, outra forma acentuada inadequadamente pelos estudantes hispânicos foi na palavra 'demografia' escrita como 'demografía', por influência do espanhol, em que as vogais ' $i$ ' e ' $u$ ' tônicas de hiato são acentuadas graficamente. No português, essas vogais só receberão acento gráfico se precedidas de outra vogal (ex.: 'caí' e 'baú').

Embora a gramática normativa do português determine que, em casos nos quais 'i' e 'u' tônicos são hiatos e são precedidos de vogais, os mesmos sejam acentuados graficamente, e também a gramática do espanhol, a omissão do acento na palavra 'país' e seu plural 'países' ocorreu em dados de nove dos dez informantes hispânicos.

Nas formas 'as pessoas tem' e 'eles tem', com o verbo 'ter' escrito sem acento circunflexo, é possível que haja uma falta de conhecimento sobre o uso do acento gráfico no verbo 'ter' para designar plural, dado o pouco tempo de estudo formal da língua.

Chama a atenção o fato de os hispânicos não acentuarem palavras em português que, em sua língua materna, também recebem acento gráfico, como em 'ultimos, academico ${ }^{3}$, unica, pais (para país). Esse resultado também é corroborado por Durão (2004) que afirma que os alunos costumam construir hipóteses sobre a língua não nativa com base em sua língua materna e, às vezes, recusam estruturas semelhantes ou iguais a sua língua, por considerar em que, desta forma, estão usando outra língua.

No caso da palavra 'língua' redigida sem acento gráfico, acredita-se que as regras de acentuação do espanhol tenham influenciado na omissão 
do acento agudo em português, já que naquele idioma paroxítonas terminadas em vogais não recebem acento (ex.: 'lengua', 'puerta'). De forma semelhante, ao não acentuar o vocábulo 'ninguém', que, em português é uma oxítona, o sujeito faz uso de regras do espanhol que preconiza que o vocábulo deve ser paroxítono (ex.: álbum,islam, item).

O terceiro critério que contempla os 'aspectos morfossintáticos' trata das dificuldades de concordância do sintagma verbal ou nominal, inadequações verbais, troca de gênero, bem como a inadequação da preposição. Considerando as questões relativas à concordância do sintagma verbal ou nominal, observaram-se duas ocorrências, 'eu conhece', em que o pronome de primeira pessoa concorda com o verbo de terceira pessoa; e 'paises hispanofalante', em que houve falta de concordância nominal. Os dois casos não estão relacionados com a língua materna do aprendiz, já que, no espanhol, a concordância de sintagma nominal e verbal também é obrigatória na norma culta.

No que tange à troca de gênero, observaram-se três casos: 'seus origens, uma deles, a lixo'. Nessas grafias, com exceção de 'em cada uma deles', em que parece ter havido um equívoco na grafia, já que a frase era 'desenvolvimento diferente em cada uma (estado) deles', é evidente a influência da língua materna do aprendiz, já que tanto a palavra 'origem' quanto 'lixo', que em espanhol são redigidas como 'origen' e 'basura' têm gênero diferente do português. A primeira é masculina e a segunda, feminina.

Considerando os casos de inadequação verbal, nas grafias 'tenhia', para 'tinha' e 'estem', para 'estejam', parece haver uma mistura de radicais e desinências da língua nativa com a língua não nativa. Para Durão, parece que o pouco conhecimento dos estudantes sobre a língua não nativa faz com que haja um emprego de morfemas de uma língua e radicais da outra. Outros casos como 'trocar a maneira de pensar', 'se poderia escolher' e 'teve' revelam que o estudante emprega formas existentes em português, mas que, no contexto usado, não são adequadas, devendo ser produzidas como 'mudar', 'pudesse' e 'tive', respectivamente. Nestes casos, os dados revelam um conhecimento de formas verbais da nova língua, embora sejam empregadas inadequadamente nas construções frasais.

Nos dados relativos à inadequação da preposição, observa-se que em 'cheguei a Brasil' há uma influência direta da língua materna do aprendiz, pois, no espanhol, a preposição para o verbo 'llegar' é 'a', e, não, 'em', assim como em 'conheço um pouco de Brasil', cuja preposição 
utilizada no espanhol seria 'de' e, não, 'do'. No caso de 'em a universidade', o sujeito deveria unir a preposição 'em' mais o artigo 'a', resultando na contração 'na'; no entanto, essa produção também pode ser resultante de sua LM, já que, em espanhol, as únicas contrações existentes são 'al' e 'del'. Em espanhol, portanto, essa forma não seria contraída, sendo escrita como 'en la'.

\section{Conclusões}

O levantamento dos dados de escrita a partir de uma das produções textuais de cada imigrante permitiu elucidar, de forma recorrente, casos em que os informantes fazem: (i) transferências dos padrões fonético-fonológicos de suas línguas; (ii) confusões na relação grafema e fonema; (iii) trocas ou supressões do acento gráfico; (iv) inadequações na concordância verbal ou nominal; (v) inadequação no uso de artigos e preposições; inadequação na flexão de gênero e número. Esses aspectos, embora não sejam exatamente os mesmos para todas as produções e nos grupos investigados, são recorrentes dentro do mesmo grupo e também entre os grupos.

A partir desse levantamento, ainda que não exaustivo, tem-se o entendimento de que este estudo pode vir a contribuir para futuras pesquisas que envolvam as línguas investigadas, e mais precisamente para o trabalho com português para falantes de outras línguas, auxiliando no preparo do material didático com focos em dificuldades reais que caracterizam os grupos em investigação. 


\section{TEACHING OF PORTUGUESE TO SPEAKERS OF OTHER LANGUAGES: AN ANALYSIS OF TRANSFERS FROM THE MOTHER TONGUE INTO WRITING}

\section{ABSTRACT}

This study deals with the acquisition of Brazilian Portuguese by speakers of other languages, more precisely regarding writing. The proposal was to investigate how these speakers develop the written system in the non-native language, observing possible influences of the standards of their native languages, more precisely concerning phonetic-phonological and morphosyntactic aspects. The study was developed from a sample of written productions collected from immigrants, who live in the cities of Rio Grande - RS and Pato Branco - PR. Altogether, 17 informants were included in the sample, with seven native speakers of the Haitian Creole and 10 native speakers of Spanish. The analysis revealed that, in terms of phonetic and phonological aspects, both Haitians and Hispanics present changes in phonemes and accents (insertions, deletions and phoneme exchanges or accent position) in written production, and considering the morphosyntactic aspects, the changes evidenced relate to nominal and verbal agreement, prepositional regency, as well as issues of grammatical gender change.

KEY-WORDS: language acquisition; immigrant; phonic aspect; morphosyntactic aspect; writing.

NOTAS

${ }^{1}$ One cannot use French grammar as a model for understanding Creole grammar.

${ }^{2} \mathrm{O}$ estudo faz parte de um projeto de pesquisa sobre a aprendizagem do português por imigrantes, avaliado pelo Comitê de Ética em Pesquisa da Universidade Tecnológica Federal do Paraná, CAAE - 55244716.3.0000.5547. 
${ }^{3}$ No caso da palavra 'acadêmico' do português, a única diferença é que, em espanhol, a mesma recebe acento agudo, sendo redigida como 'académico', mas ambas as palavras são proparoxítonas.

\section{REFERÊNCIAS}

BISOL, L. O acento: Duas alternativas de análise. Organon, Porto Alegre, v. 28, n. 54, p. 281-321, jan./jun. 2013.

BRISOLARA, L.B. A relação entre a consciência fonológica e a aquisição da escrita por jovens e adultos. In: LAMPRECHT, R. R. et al. Consciência dos sons da língua: subsídios teóricos e práticos para alfabetizadores, fonoaudiólogos e professores de língua inglesa. 2. ed. Porto Alegre: EdiPUCRS, 2012, p.121-138.

CADELY, J. Les sons du Creole haïtien. The Journal of Haitian Studies, vol. 9, n. 2, 2004.

DURÃO, A. B. A. B. Análisis de Errores en la interlengua de brasileños aprendices de español y de españoles aprendices de portugués. Londrina: Eduel, 2004.

HUALDE, J. I; OLARREA, A; ESCOBAR, A. M; TRAVIS, C. E. Introducción a la lingüística hispánica. New York: Cambridge University Press, 2010.

LANZA, A. L; LAMOUNIER, M. L. A América Latin como destino dos imigrantes: Brasil e Argentina (1870 - 1930). Cadernos Prolam/USP, v. 14, p. 90 $-107,2015$.

LEE, S-H. O acento primário do português do Brasil. Revista Estudos da Linguagem. Belo Horizonte, v.6, n.2, p.5-30, jul./dez. 1997.

MACHRY DA SILVA, S. Aprendizagem do português por imigrantes haitianos: percepção das consoantes /1/ e /r/. Ilha do Desterro, vol. 70, nº 3, pág. 47-61. MARTINS, M. G. A aquisição da Língua Portuguesa por Imigrantes Haitianos em Porto Velho. Dissertação (Mestrado) - Fundação Universidade Federal de Rondônia, 2013.

MIRANDA, A. R. M. Um estudo sobre o erro ortográfico. In: Otília Lizete Heining, Cátia de Azevedo Fronza. (Org.). Diálogos entre linguística e educação. 1 ed. Blumenau: EDIFURB, 2010, v. 1, p. 141-162.

NAVARRO TOMÁS, T. Manual de pronunciación española. Madrid: Consejo Superior de Investigaciones Científicas, 2004.

PIMENTEL, M. L; COTINGUIBA, G. C; RIBEIRO, A. S. O crioulo haitiano e 
seu reconhecimento político. Universitas Relações Internacionais, vol. 14, n. 1, jan/junh/2016.

REAL ACADEMIA ESPAÑOLA, ASOCIACIÓN DE ACADEMIAS DE LA LENGUA ESPAÑOLA. Nueva gramática de la lengua española - Fonética y fonología. $1^{\mathrm{a}}$ ed. Barcelona: Espasa libros, 2011.

RODRÍGUEZ PUÉRTOLAS, J. et al. Lengua Castellana y Literatura. $2^{0}$ Bachillerato. Madrid: Ediciones Akal, S.A., 2004.

SILVA, A. P. Uma ferramenta para o Ensino do acento primário do PB para falantes nativos do Crioulo Haitiano. Organon, vol. 30, n. 58, p. 175 - 191, jan/ junh, 2015.

SPEARS, A. Introduction: he Haitian Creole language. In.: The Haitian Creole language. Lanham, MD: Lexington Books/ Rowman \& Littleield, 2010.

VALDAM, A. Ann Pale Kreyòl: an introductory course in Haitian Creole. Washington: Indiana University, 1988.

VILLENOUVE; A-J; SIEGEL, J; VALDMAN, A. Morphophonological Variation in Haitian Creole: the Case of 3SG. University of Pennysylvania Working Papers in Linguistics, vol. 19, 2013.

ZIMMER, M; ALVES, U. K. A produção de aspectos fonéticos/fonológicos da L2: instrução explícita e conexionismo. Linguagem \& Ensino, v. 9, n.2, p. 145 -175 , julh/dez, 2006.

Recebido: 25/01/2018

Aceito: 10/06/2018 